\title{
Vivir con lo justo. Estudios de historia social del trabajo en perspectiva de género. Argentina, siglos XIX y XX
}

Andrea Andújar, Laura Caruso, Florencia Gutiérrez, Silvana Palermo, Valeria Silvina Pita y Cristiana Schettini (2016)

Prohistoria Ediciones, Rosario, 160 pp. - Col. Universidad, 52

\section{(1) Luisina Agostini. UNL - UNR - CONICET}

Los trabajos reunidos en este libro abonan los estudios sobre las historias de hombres y mujeres que trabajan en diferentes espacios y oficios entre fines del siglo XIX y primera mitad del siglo XX en la Argentina. El abordaje que las autoras proponen de las formas de vida de estas personas, el análisis de sus reclamos y acciones, las características de sus ocupaciones exponen un abanico de experiencias documentadas que contribuyen a ampliar una historia del trabajo más allá del movimiento obrero organizado. Nos encontramos con una propuesta que tiene como eje la lucha por los derechos vulnerados y que indaga los sentidos que los sujetos le asignaron a lo que creían era justo o injusto para sus vidas.

Valeria Pita realiza un estudio del escenario social constituido en Buenos Aires durante la epidemia de fiebre amarilla de 1871 y reflexiona sobre las formas de vivir y modos de trabajar en la ciudad porteña, teniendo en cuenta las concepciones de higiene, salud y "buen vivir" que circulaban y que generaron disputas y tensiones a la hora de regular los espacios públicos y privados de la ciudad, como también las formas de inspección y control que se conformaron según las necesidades de la epidemia. Esto le permite cruzar fuentes para poder indagar en los roles y/o papeles públicos de los sujetos y ver las diferencias sociales, el imaginario de la elite porteña con respecto a los inmigrantes. Se hace evidente el prejuicio existente de quienes venían de las familias más encumbradas sobre los hombres y mujeres trabajadores e inmigrantes, a quienes asociaban con prácticas negativas que justificaban los desalojos, las clausuras e intervenciones en sus espacios habitados. Comisionados, inspectores municipales y agentes policiales eran los sujetos que controlaban el espacio público y se inmiscuían en los ámbitos privados bajo las banderas del higienismo y la salubridad, generando informes y acciones basados en consideraciones de clase y género hacia los trabajadores que defendían sus derechos y sus formas de vida. También el artículo indaga en las definiciones institucionales que evidenciaban los intentos de los sectores más altos de la población porteña por monopolizar el poder público erigiéndose en jueces moralmente responsables de regular espacios de la ciudad en una coyuntura apremiante que les otorgaba peligrosidad y desprecio a formas ya existentes de habitar y trabajar. El aporte de Pita consiste en visibilizar los casos de personas trabajadoras, nativas y/o extranjeras que sufrieron estigmatización, segregación, abuso de autoridad, y realizaron reclamos para defenderse. Parecía ser que estas situaciones generaron un complejo escenario político social donde las atribuciones de las autoridades fueron puestas en tela de juicio y tensión cuando se trataba de casos injustos e infundados y cuando las concepciones sobre la higiene también eran tomadas por los trabajadores como bandera para sostener sus denuncias.

El artículo de Cristiana Schettini trabaja sobre la sociabilidad construida en la ciudad porteña de fines del siglo XIX, pero, en este caso, para indagar en las formas de reglamentar el espacio del prostíbulo. La municipalidad y la policía son las instituciones que aparecen fuertemente relacionadas con esa tarea en un clima de expansión del higienismo y de la redefinición de la traza urbana porteña. La autora recorre la legislación que le permite inmiscuirse en la vida cotidiana de los porteños y los intereses por el negocio del prostíbulo que se presentaban en los sectores más altos de la sociedad. De esta manera, 
recrea la geografía de estos ámbitos, la constitución de espacios destinados a esas prácticas y las tensiones en torno a su reglamentación. Afirma que el reglamento de 1875 contaba con definiciones sobre los lugares donde se debían radicar las casas y la creación de la Regente, como figura reguladora del funcionamiento interno de los lugares e interlocutora con las instituciones municipales y policía, por lo que resulta clave a la hora de estudiar los conflictos y disputas por la regulación y habilitación de estas casas. La disposición de zonas "morales" frente a otras impropias se generaliza en la ciudad porteña dando cuenta de un imaginario cultural segregacionista y conservador que distinguía las buenas costumbres de las otras. También escondía los intereses inmobiliarios de las familias con alto poder adquisitivo, que cuestionaban y denunciaban estos lugares para que fueran desalojados y poder constituir allí emprendimientos urbanos.

En estos dos capítulos podemos leer, desde la historia social que privilegia la perspectiva de género, diferentes formas de ocupar los espacios y organizar la vida cotidiana porteña a fines del siglo XIX. Encontramos en estos trabajos una preocupación por estudiar a los sujetos construyendo espacios, ocupándolos, circulando en ellos y otorgándoles significados diferentes que se relacionan con un ordenamiento social jerarquizado que posibilita o clausura formas de habitar y trabajar. En esta parte del libro se recuperan situaciones donde hombres y mujeres son protagonistas de la defensa de sus trabajos y sus hogares. Sus palabras y acciones que se reflejan en las fuentes presentadas evidencian conflictos sociales que encierran concepciones sobre un determinado orden social atravesado por relaciones de poder y género como también de clase. Las relaciones de poder que parecen ser favorables a los grupos de vecinos respetados tienen fisuras cuando los sujetos que forman parte del grupo de los "inmorales" despliegan argumentos sólidos para defender sus lugares en la ciudad. También las autoras, mediante el corpus documental, pueden desentrañar las características de las instituciones de gobierno locales, sus funciones, los alcances y limitaciones de sus intervenciones. Indagar las disputas de intereses entre quienes se afanaban de ocupar los cargos más importantes para decidir sobre cuáles eran las formas propias de vivir y habitar la ciudad y cuáles eran aquellas impropias, impuras, que no casualmente correspondían a hombres y mujeres de los sectores trabajadores. Buenos Aires es retratada como un escenario de definiciones institucionales, donde el poder circulaba entre varios actores locales mediante intervenciones y abordajes de los conflictos, preocupados por regular y disciplinar una sociedad en crecimiento y heterogénea en su composición como en sus ideologías.

El siglo XX, para los trabajadores en la Argentina, se presenta cargado de acciones colectivas que hacen de la defensa del oficio y de las conquistas sindicales elementos importantes para pensar la impronta de las comunidades obreras en la configuración de las identidades sociales y localmente situadas. Los capítulos que se presentan a cargo de Laura Caruso, Silvana Palermo, Andrea Andújar y Florencia Gutiérrez narran las experiencias de los trabajadores en la constitución de sus espacios laborales, mayoritariamente masculinos, durante la primera mitad del siglo XX. También se ocupan de escrudiñar las redes de sociabilidad construidas entre los obreros y otros actores sociales, como los gremios, las familias y las mujeres, para poder dar cuenta de la existencia de comunidades ocupacionales y/u obreras en diversos espacios del país.

La propuesta de Laura Caruso indaga el mundo de los trabajadores de a bordo del puerto de Buenos Aires en el contexto de la Primera Guerra Mundial y la posguerra. Podría pensarse que los obreros embarcados carecían de organización gremial y laboral propia y constante; sin embargo, la autora se ocupa de desentrañar, por un lado, las particularidades del trabajo en el barco, y por otro, las formas en que el espacio configura identidades laborales, sindicales y fortalece un ideario masculino que se articulaba en el hombre como trabajador y tripulante. El barco condensaba una organización jerárquica y disciplinaria; el gremio marítimo formaba parte importante de la dinámica de esa comunidad ocupacional al imprimir nociones de solidaridad entre los tripulantes y trabajadores para poder desafiar las características del trabajo fragmentado y jerárquico.

La Federación Obrera Marítima (FOM) se ocupó de generar vínculos frente a las tensiones de la vida de a bordo construyendo una idea de familia fomista. Lo particular es que los trabajadores se constituyeron en el masculino dentro de una visión idílica donde la FOM aparece como el lugar de cuidado, la madre protectora de gran fortaleza y presencia, el sentido femenino entronizado en la figura gremial que se acompañaba de una "liturgia marítima". La existencia del mundo fomista se plasmaba en un discurso que colocaba a los obreros marítimos como soldados de la FOM por su fortaleza moral y física, su lucha, valentía y organización, apelaciones que tensionaban con los ideales masculinos. Esta relación entre el gremio y los trabajadores creaba una identidad particular y diferente a la encabezada por políticas 
paternalistas en otros espacios y oficios, como por ejemplo el mundo del trabajo ferroviario que Silvana Palermo analiza.

El estudio de la huelga ferroviaria de 1917 le permite a Palermo visibilizar ideales asociados a la masculinidad que serán sostenidos como parte del discurso reivindicativo de esos años. En este artículo se explica la relación entre el mundo laboral y el espacio privado del hogar y que el "buen porvenir" estaba asociado a la carrera en el ferrocarril. El varón como proveedor de la familia verá su condición de trabajador vulnerada y por eso no solo reclamará lo que atañe a las cuestiones del oficio, sino que sostendrá un discurso atravesado por las relaciones de género y poder, visibilizando los roles asignados en el imaginario social a hombres y mujeres. Frente a la crisis laboral ferroviaria, las mujeres tendrán una participación importante mostrando la presencia de la familia ferroviaria en huelga.

Andújar estudia las huelgas petroleras de 1932 en Comodoro Rivadavia recorriendo los ámbitos donde se llevaron a cabo; también muestra cómo en los campamentos petroleros se construyeron diferentes vínculos, laborales, familiares, políticos, de género, de clase exponiendo una comunidad donde las nociones de lo justo e injusto tienen un significado particular. En este trabajo podemos conocer experiencias personales y colectivas de lucha que la autora utiliza no solo para explicar los conflictos en sí mismos, sino para mostrar la cotidianeidad de la vida en la Patagonia petrolera. Las reivindicaciones que los trabajadores y su comunidad sostienen están atravesadas por situaciones de explotación de clase, que tienen que ver con la singularidad del trabajo petrolero y con la influencia del Partido Comunista, de la corriente anarco sindicalista y del sindicato de filiación comunista Unión General de Obreros Petroleros (UGOP).

Florencia Gutiérrez, por su parte, toma como disparador de su abordaje el testimonio de un trabajador de la zafra tucumana para poder inmiscuirse en el mundo laboral azucarero que desde fines del siglo XIX carecía de experiencias asociativas estables. Le interesa estudiar la irrupción y desarrollo de la Federación Obrera Tucumana de la Industria Azucarera (FOTIA) en 1944 y sus alcances como ordenador de esa comunidad obrera preexistente para poder rescatar las formas en que esa organización gremial alimentó nociones de masculinidad y clase previamente presentes. El mundo del trabajo azucarero formuló reivindicaciones durante el peronismo que estuvieron atravesadas por las características de un mundo laboral donde existían abusos jerárquicos y sexuales hacia mujeres que carecían de trabajo formal porque los hombres eran quienes asumían el vínculo contractual. En este sentido, la realidad del trabajo en la zafra escondía situaciones y experiencias laborales que no estaban regladas, imperaba una masculinización de la mano de obra y una organización piramidal y centralizada de los procesos productivos. Las mujeres fuera de la fábrica se vinculaban de diferente manera con la patronal, y esto evidenciaba divisiones sexuales y sociales de trabajo.

Este libro contribuye históricamente con investigaciones que permiten complejizar y estudiar los mundos laborales y las formas de vivir de los sectores trabajadores donde sus experiencias son protagonistas centrales de las explicaciones que las autoras construyen. Los escenarios de lucha obrera, públicos, se analizan con referencia a los espacios privados donde transitan cotidianamente los actores sociales. Estos individuos no son estudiados de forma aislada, sino que son sus vínculos, sus relaciones de género, sociales, políticas, económicas que los atraviesan, les dan sentido a sus acciones y los interpelan como sujetos insertos en el barrio, la ciudad, el gremio, el trabajo, en comunidades obreras las cuestiones que se desarrollan en el libro y abonan el campo historiográfico. Las explicaciones construidas enriquecen las maneras diversas en que los hombres y mujeres entendieron y lucharon por lo que creían era justo, y nos dicen sobre sus valores e intereses, es decir, sobre sus identidades.

Podemos preguntarnos ¿cómo se forman las comunidades obreras? ¿Son creaciones desde arriba, desde las empresas, desde el Estado, o son construidas desde abajo por los trabajadores? ¿Qué participación tienen los gremios en esas conformaciones obreras? Estudiar las huelgas ferroviarias, petroleras, y atender a la singularidad del trabajo azucarero son casos que permiten dar algunas respuestas a esos interrogantes porque a partir del análisis de conflictos o alteraciones de la normalidad laboral es que encontramos la existencia y podemos explicar el funcionamiento del mundo de estos trabajadores. Lo particular de los aportes de estas autoras radica en que complejizan la mirada sobre el universo sindical, entienden que para explicar por qué luchan los obreros o qué reclaman y cómo lo hacen deben atender a la relación entre el trabajo, la familia, el barrio, la organización gremial y la patronal. Estos actores se ponen en juego para constituir entramados laborales y sociales que devienen de nudos laborales particulares. 
